\title{
Retrospective Evaluation of Radiographic Findings in Patients with Pulmonary Tuberculosis: An Observational Study
}

\author{
Nitin Dasrath Wadhwani ${ }^{1}$, Niranjan Bapusaheb Patil ${ }^{2}$ \\ ${ }^{1}$ Professor \& HOD, Department of Radiodiagnosis, D.Y. Patil Medical College, Kolhapur, ${ }^{2}$ Professor, Department of Radiodiagnosis, D.Y. Patil Medical College, \\ Kolhapur.
}

\section{Abstract}

Background: Tuberculosis remains a worldwide health hazard instead well documented well publicized methods of prevention and cure. Chest radiographs are used to stratify for risk and to assess for asymptomatic active disease. Hence; we planned the present study to retrospectively analyze the data of the pulmonary tuberculosis patients for analyzing the spectrum of radiographic findings. Subjects and Methods: In the present study, we analyzed the data records of a total of 100 pulmonary tuberculosis patients. A self-framed master cart was prepared in which, past medical history, clinical history, radiographic findings, clinical findings of all the patients was obtained. Data records of only those patients were analyzed in which both clinical and bacteriologic confirmation of the disease was present. Radiographs were evaluated. Only preoperative radiographic findings were taken into consideration. Results: The most common radiographic finding was hilar lymph node, found to be present in 66 percent of the patients. Unilateral nodular infiltration was found to be present in 25 percent of the patients. Patchy consolidation was seen in 22 percent of the patients. Fibrotic scar was seen in 10 percent of the patients while calcified nodule was seen in 8 percent of the patients. Conclusion: In diagnosing and assessing the extent of severity among tuberculosis patients, radiographic imaging is a vital tool.

Keywords: Pulmonary, Tuberculosis, Radiological.

Corresponding Author: Dr. Niranjan Bapusaheb Patil, Professor, Department of Radiodiagnosis, D.Y.Patil Medical College, Kolhapur.

Received: June 2019

Accepted: June 2019

\section{Introduction}

Tuberculosis remains a worldwide health hazard instead well documented, well publicized methods of prevention and cure. Poverty and HIV infection are main causes for its persistence. Most tuberculosis programmers use direct smear examination of sputum but, if resources permit, culture is desirable. ${ }^{[1-3]}$ Reliable susceptibility testing is a luxury few developing countries can afford, although it is especially desirable for purposes of re-treatment. Chest radiographs are used to stratify for risk and to assess for asymptomatic active disease. ${ }^{[4-6]}$ Sequelae of previous tuberculosis that is now inactive manifest characteristically as fibro nodular opacities in the apical and upper lung zones. Stability of radiographic findings for 6 months distinguishes inactive from active disease. ${ }^{[7,8]}$ Hence; under the light of above mentioned data, we planned the present study to retrospectively analyze the data of the pulmonary tuberculosis patients for analyzing the spectrum of radiographic findings.

\section{Subjects and Methods}

The present study was conducted in the department of radio-diagnosis of the medical institute and it included retrospectively analysis the data of the pulmonary tuberculosis patients for analyzing the spectrum of radiographic findings. Ethical approval was obtained from institutional ethical committee and written consent was obtained after explaining in detail the entire research protocol. In the present study, we analyzed the data records of a total of 100 pulmonary tuberculosis patients. Inclusion criteria for the present study included:

- Subjects more than 18 years of age

- Subjects with absence any other form of systemic illness,

- Subjects in which complete data records was available

- Diabetic and hypertensive subjects

After meeting the inclusion criteria, data records of all the patients were obtained. A self-framed master cart was prepared in which, past medical history, clinical history, radiographic findings, clinical findings of all the patients was obtained. Data records of only those patients were analyzed in which both clinical and bacteriologic confirmation of the disease was present. Radiographs and computed tomography scans were evaluated. Only preoperative radiographic findings were taken into consideration in the present study. All the results were recorded in Microsoft excel sheet and were analyzed by SPSS software. 


\section{Results}

[Figure 1] shows age-wise distribution of patients. In the present study, mean age of the patients was 41.8 years. Majority of the patients (48 percent) belonged to the age group of 30 to 50 years. 56 percent of the patients of the present study were males while the remaining 44 percent were females as shown in [Figure 2].

[Table 1] shows the radiographic manifestation observed in the present study. In the present study, the most common radiographic finding was hilar lymph node, found to be present in 66 percent of the patients. Unilateral nodular infiltration was found to be present in 25 percent of the patients. Patchy consolidation was seen in 22 percent of the patients. Fibrotic scar was seen in 10 percent of the patients while calcified nodule was seen in 8 percent of the patients.

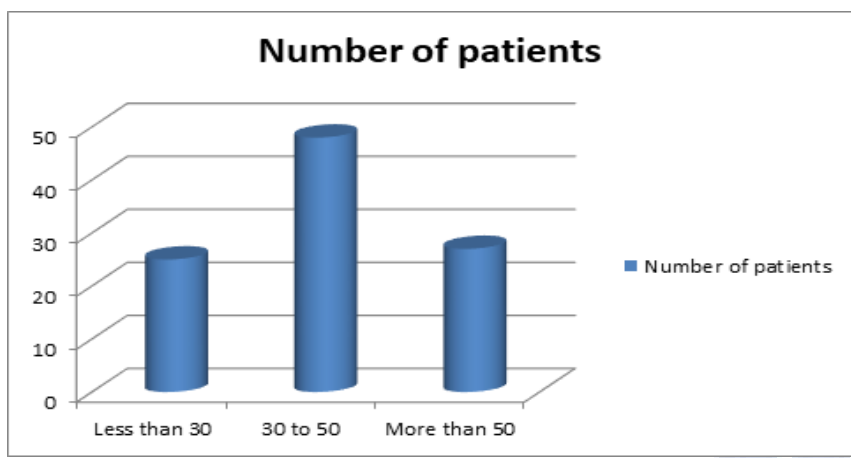

Figure 1: Age-wise distribution of patients

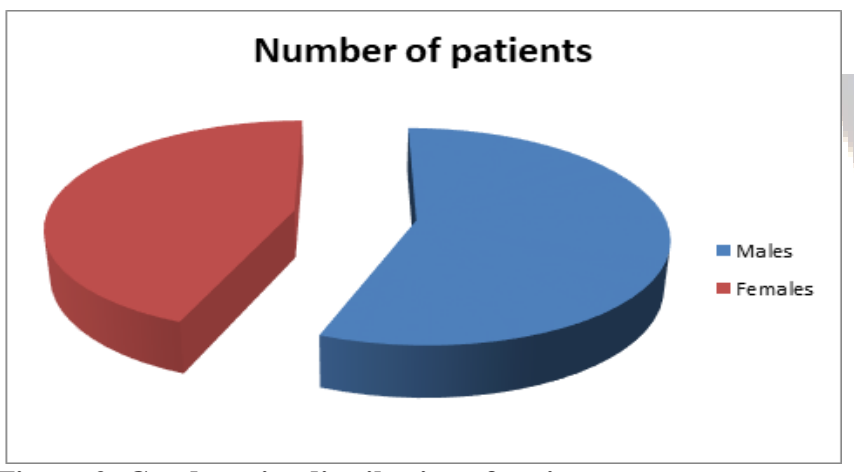

Figure 2: Gender-wise distribution of patients

Table 1: Radiographic manifestation

\begin{tabular}{|l|l|}
\hline Radiographic manifestation & Number of patients \\
\hline Unilateral nodular infiltration & 25 \\
\hline Bilateral nodular infiltration & 3 \\
\hline Patchy consolidation & 22 \\
\hline Calcified nodule & 8 \\
\hline Fibrotic scar & 10 \\
\hline Cavity & 12 \\
\hline Hilar lymph node & 66 \\
\hline Others & 8 \\
\hline
\end{tabular}

\section{Discussion}

Tuberculosis (TB) is a major challenge among infectious diseases. In recent years, the prevalence of TB has been rising globally. According to 2014 Global Tuberculosis
Report, 9 million people are estimated to have developed $\mathrm{TB}$ and 1.5 million deaths of TB patients were reported in 2013. ${ }^{[7-9]}$ The current guidelines for diagnosis of adult chest tuberculosis (TB) are based primarily on the demonstration of acid-fast bacilli (AFB) on sputum microscopy. Chest radiograph (CXR) finds its place in sputum-negative patients not responding to a course of antibiotics. ${ }^{[6-8]}$ In the present study, majority of the patients (48 percent) belonged to the age group of 30 to 50 years. 56 percent of the patients of the present study were males while the remaining 44 percent were females as shown in [Figure 2]. TB can affect any organ system, although manifestations are most commonly related to the chest. The lungs are the most common and often the initial site of involvement. Chest involvement is most commonly pulmonary, followed by lymph nodal and pleural disease.

Radiology remains one of the most important diagnostic modalities of tuberculosis infection. Radiological manifestations of pulmonary tuberculosis are dependent on several host factors, including underlying immune status. Impaired host immunity like HIV infection, diabetes mellitus etc., have been regarded as a predisposing factor in tuberculosis. Endobronchial spread of disease, cavitatory lesions and lymphadenopathy can be easily detected by Computed Tomography (CT). Pleural effusion and bronchopleural fistula can also be detected in early stages. The most common CT findings of reactivation pulmonary TB are centrilobular small nodules, branching linear and nodular opacities present as 'tree-in-bud' sign, patchy or lobular areas of consolidation, and cavitation. Cavitation usually indicates active disease. ${ }^{[10]}$

In the present study, the most common radiographic finding was hilar lymph node, found to be present in 66 percent of the patients. Unilateral nodular infiltration was found to be present in 25 percent of the patients. Patchy consolidation was seen in 22 percent of the patients. Fibrotic scar was seen in 10 percent of the patients while calcified nodule was seen in 8 percent of the patients. Lachi $\mathrm{T}$ et al described the radiological findings of pulmonary tuberculosis in indigenous patients from the city of Dourados, MS, Brazil, according to age and sex. Chest radiographic images of 81 patients with pulmonary tuberculosis, acquired in the period from 2007 to 2010, were retrospectively analyzed by two radiologists in consensus for the presence or absence of changes. The findings in abnormal radiographs were classified according to the changes observed and they were correlated to age and sex. The individuals' ages ranged from 1 to 97 years (mean: 36 years). Heterogeneous consolidations, nodules, pleural involvement and cavities were the most frequent imaging findings. Most patients $(55 / 81$ or $67.9 \%)$ were male, and upper lung and right lung were the most affected regions. Fibrosis, heterogeneous consolidations and involvement of the left lung apex were significantly more frequent in males $(p<0.05)$. Presence of a single type of finding at radiography was most frequent in children $(\mathrm{p}<0.05)$. Based on the hypothesis that indigenous patients represent a population without genetically determined resistance to tuberculosis, the present study may enhance the knowledge about how the pulmonary form of this disease manifests in susceptible individuals. ${ }^{[11]}$ 


\section{Conclusion}

From the above obtained results, it can be concluded that in diagnosing and assessing the extent of severity among tuberculosis patients, radiographic imaging is a vital tool.

\section{References}

1. Coker R, McKee M, Atun R, Dimitrova B, Dodonova E, Kuznetsov S, et al. Risk factors for pulmonary tuberculosis in Russia: case-control study. BMJ 2006;332: 85-7.

2. Yuen CM, Tolman AW, Cohen T, Parr JB, Keshavjee S, Becerra MC. Isoniazid-resistant tuberculosis in children: a systematic review. Pediatr Infect Dis J. 2013;32:e217-e226.

3. Tackling poverty in tuberculosis control. Lancet 2005;366: 2063.

4. Dye C. Global epidemiology of tuberculosis. Lancet 2006;367: 93840 .

Copyright: (C) the author(s), publisher. Asian Journal of Medical Radiological Research is an Official Publication of "Society for Health Care \& Research Development". It is an open-access article distributed under the terms of the Creative Commons Attribution Non-Commercial License, which permits unrestricted non-commercial use, distribution, and reproduction in any medium, provided the original work is properly cited.

How to cite this article: Wadhwani ND, Patil NB. Retrospective Evaluation of Radiographic Findings in Patients with Pulmonary Tuberculosis: An Observational Study.Asian J. Med.Radiol. Res. 2019;7(2):01-03.

DOI: dx.doi.org/10.21276/ajmrr.2019.7.2.1

Source of Support: Nil, Conflict of Interest: None declared.
Dormandy T. The white death. London: Hambledon Press, 1999.

6. Long S, Pickering LK, Prober CG. Principles and practice of pediatric infectious diseases. 4th edition. 2012.

7. World Health Organization. Global Tuberculosis Report. Geneva: World Health Organization; 2013.

8. International Diabetes Federation. Diabetes Atlas. 6th ed. Brussels: International Diabetes Federation; 2014.

9. Baghaei P, Marjani M, Javanmard P, Tabarsi P, Masjedi MR. Diabetes MetabDisord. 2013;12:58

10. Mathur M, Badhan RK, Kumari S, Kaur N, Gupta S. Radiological Manifestations of Pulmonary Tuberculosis - A Comparative Study between Immunocompromised and Immunocompetent Patients. J ClinDiagn Res. 2017;11(9):TC06-TC09.

11. Lachi T, Nakayama M. Radiological findings of pulmonary tuberculosis in indigenous patients in Dourados, MS, Brazil. Radiol Bras. 2015;48(5):275-281. doi:10.1590/0100-3984.2014.0070 mellitus and tuberculosis facts and controversies. J Diabetes
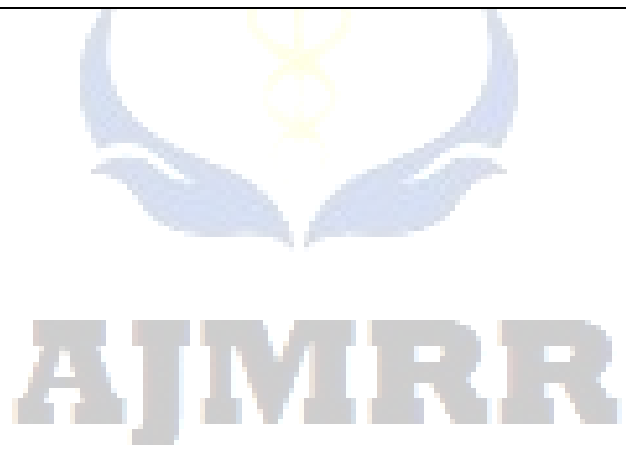